\title{
The Shadow that Hovered Over: Gender Salience in Eating Disorder Recovery
}

\author{
Connor B. S. Strobel ${ }^{1,2}$ (D)
}

Accepted: 13 January 2022 / Published online: 2 March 2022

(c) The Author(s) 2022

\begin{abstract}
Studies examining the social forces behind eating disorders have found that unrealistic conceptions of feminine beauty exert pressure on millions of women suffering from eating disorders. However, untenable feminine ideals do not explain the social factors affecting men. Utilizing narrative and content analyses of accounts of women and men on Tumblr and eating disorder recovery support groups, this paper finds that men experience eating disorders and recover differently from women. Gender salience, and not simply femininity, had a powerful effect on the recovery process for both women and men. Drawing from the sociologies of narrative, gender, and masculinity studies, this study provides a more nuanced and consequential way of understanding eating disorder recovery and how recovery trajectories vary by gender. Four categorical narrative types emerged from the sample: Ecological, Sickened, Abused, and Warrior. Language in the narratives relied on traditional gender roles, and each narrative lead to different proportions of recovery outcomes. Individuals in this study used one of four narrative types. The warrior narrative, which was the only one used by men, was associated with a higher rate of relapse. The propensity to relapse varied between the narrative types, suggesting some may be more conducive for recovery.
\end{abstract}

Keywords Eating disorders $\cdot$ Masculinity $\cdot$ Narratives $\cdot$ Gender salience

\section{Introduction}

Over 30 million Americans suffer from eating disorders [29, 33, 60, 66]. Eating disorders "are characterized by a persistent disturbance of eating or eating-related behavior that results in the altered consumption or absorption of food and that

Connor B. S. Strobel

cstrobel@uci.edu

1 Department of Sociology, University of California Irvine, Irvine, CA, USA

2 Irvine, CA, USA 
significantly impairs physical health or psychosocial functioning" [1]. The Diagnostic and Statistical Manual (DSM-5) recognizes eight types of eating disorders: anorexia nervosa, bulimia nervosa, binge-eating disorder, pica, rumination disorder, avoidant/restrictive food intake disorder, other specified feeding and eating disorders (OSFED), and unspecified feeding or eating disorder (UFED). The factors driving individuals into disorder are social, neuro-chemical, and psychological $[60,66]$. Most individuals who suffer from eating disorders hold a combination of these factors, none being necessary nor sufficient (ibid). In addition, eating disorders have debilitating physical, psychological, and social effects throughout the lives of sufferers [29, 33]. The effects are often chronic, debilitating, and can have long-term physical, psychological, and social consequences on individuals, their family, and community,even resulting in death.

Understanding the consequential social factors in an individual's recovery are crucial in improving the quality of treatment, to improve commonplace understanding of eating disorders and those who have them, and to combat stigma. The digital space is increasingly important in one's development and maintenance of self. As a result, activity on support group forums and social media are used as a part of recovery regimens by therapists and clinicians and is especially valuable for those without access to physical support groups and treatment centers. This paper uses online support group forums and social media platforms at its research sites. This research also engages with and synthesizes research within the sociologies of narrative and gender, and masculinity studies, arguing that gender identity salience, expressed by through gender roles and gendered language in recovery narratives, are consequential in the recovery outcomes of both men and women with eating disorders.

Stereotypes about those with eating disorders suggest that a person with an eating disorder looks like a frail, Caucasian female in her early 20's. Consistent with that, scholarship in sociology, clinical psychology, and gender studies has focused on the causes of eating disorders in females (for a review see [26]. Social-psychological pressures because of an unrealistic conception of an ideal feminine body have been routinely shown to have a significant influence for many in developing an eating disorder and to be major inhibitors of a full recovery from them. Furthermore, the normative pressures affecting women do not appear the same for the over 10 million men in the United States with eating disorders, many of whom hold highly masculine conceptions of ideal male bodies [66]. By performing a narrative analysis of original data from 200 accountholders on social media and eating disorder support forums, I examine how the experiences of eating disorders and recovery vary by gender. Individuals in the study utilized one of four narratives: Ecological, Sickened, Abused, and Warrior. The findings of this research illustrate that beliefs about gender roles and gender stereotypes were consequential for both men and women, and that they relied on distinctly gendered roles and stereotypes throughout the recovery process. Moreover, this study found that the type of narrative an account holder used was more predictive of whether or not they would report relapsing or not than merely the type(s) of eating disorder they experienced. 


\section{Literature Review}

Sociology has not kept pace with the growth in scholarship on women with eating disorders in a variety of other disciplines. Social pressures related to unrealistic conceptions of feminine beauty and body image have been shown to be consequential in the development of eating disorders by women, but these explanations are not directly applicable to the 10 million American men experience eating disorders [26]. Developing a healthy body image and ideas about beauty are ubiquitous features of eating disorder recovery programs and therapy. Femininity is a major social pressure affecting many women throughout the development of and recovery from eating disorders, through the ways beauty is conceived of, gender roles are promoted both culturally and institutionally, and the phenomenological experiences of living a gendered life [71]. Yet, the role of masculinity is not as clear in the development and manifestation of eating disorders in men and their recovery from them. Sociology has not followed the increased focus in psychology, psychiatry, and neuroscience on the unique factors affecting men with eating disorders $[45,57,70]$. Given that the social world often has a profound effect on women in development, practice, and treatment of eating disorders, sociology has a unique capacity to explore the particular influences of social factors the recovery of men with eating disorders. As such, the preexisting research does not tell us if it is femininity or gender salience, more broadly, that affects the development and recovery from eating disorders.

\section{Gendered Accounts of Eating Disorders for Women}

A rich and diverse body of cross-disciplinary research has utilized sociological perspectives to gain insights into the contributing factors in developing eating disorders and affecting individual's recovery. Scholarship within the sociology of eating disorders considers the different class and race-based pressures leading to the development of eating disorders, and propensity of certain social groups in developing particular types of eating disorders. While they do not control for gender, Sublette and Martin found that many of the social norms about food etiquette that vary by socioeconomic class also correspond with the differences in the types of eating disorders by class [61]. Smith et al and Thompson found that African Americans were more likely to develop binge eating disorders and whites were more likely to develop anorexia nervosa and bulimia nervosa [58, 65].

The preponderance of sociological research on eating disorders has focused on culture aspects leading to the development of and recovery from eating disorders; from macro-, meso-, and micro-analytical perspectives. At the macro-cultural level, Saguy and Gruys have examined the ways by which the news media reproduces stereotypes about those with eating disorders and those who are overweight [53]. Wolf was at the forefront of how businesses exploit deleterious conceptions of feminine beauty and the consequences of such practices [74]. Bordo extended the cultural sociological perspective on the body, by providing a cultural history 
that explains the development of modern western beliefs about body image and oppositional forces to it [5].

At the meso-level Haworth-Hoeppner found that a critical family life and certain kinds of discourse about weight while growing up were associated with the development of eating disorders [26]. Hesse-Biber et al. found that women's ability to selectively engage in local community and culture affected their ability to recover from eating disorders [28]. Hollander has found that "beliefs about vulnerability and dangerousness are central to conceptions of gender" and that there are stark differences between men and women, especially as it relates to their bodies [30, 31: p. 83). Whitehead examined how gender is coercively used in pro-eating disorder online social groups [72]. Walstrom looked at how the talk about eating disorders is constructed in particular settings but is also structurally consistent throughout a variety of settings in which people might talk about eating disorders [67]. Wax and Cassell have advocated seeing anorexia nervosa as unique to a particular kind of culture in a stratified society [68]. Others, such as Haworth-Hoeppner and Maines and Garrett, have found that the inability for individual's identities to be sufficiently well-received in their communities can perpetuate their invalidated identities and can prevent recovery [27] (1996). Yet, none of these studies have included men in their samples. As a result, we have no basis for assessing the pervasive effect of gender and concluding whether men develop and recovery from eating disorders similarly, oppositely, or otherwise differently from women. This paper shows how these differences manifest and affect health outcomes.

\section{Gendered Accounts of Eating Disorders for Men}

The burgeoning field of masculinity studies has begun to address the consequences of the ways through which men construct themselves as men and members of a larger culture. Others have explored how men construct and maintain gender roles. Intersectional understandings of how men develop bodily aesthetics, gender norms, and gender roles have found racial differences in how men perceive beauty in women [69], the relationship between class and gender [51], the social power behind where masculine ideals come from Chen $[14,15,16,19,46)$ and how these ideals relate to men being feminists [55]. Davids and Green found that bisexual men had higher rates of eating disorder symptomology than heterosexual men but did not examine the causes for the disorders or how gender or sexual orientation affect their recovery [18].

Scholars in masculinity studies have also drawn off the insights of women's studies, emphasizing that the ways men develop their sense of masculinity is done through action and is performative [17, 47, 52; 56, 71]. Chaiken and Pliner found that the act of eating has a social dimension, with ways of eating varying by gender [10]. The scholars focused on the processes of "doing gender" have not considered the nature of the narratives that guide these performances. By articulating the narratives and used language of individuals with eating disorders in online eating disorder support groups and general social media platforms, this study reveals 
how the practice of doing gender varies between men and women seeking to recover from their disorders and how these variations lead to differences in their recovery outcomes.

There has been recent scholarship in psychology and psychiatry on men with eating disorders, with a particular emphasis on the causes, comorbidities, and diagnostic criteria (Nagana et al. 2021). That work has, for example, shown that muscle dysmorphia is a more common comorbidity in men than women and may have greater inhibition towards seeking medical care (ibid). Siegal and Sawyer's study of 14 white men and how they manage their recoveries at work despite their gendered occupational expectations is novel in looking at how masculinity shapes recovery in men with eating disorders (2020). The study highlights that an accurate self-assessment of one's recovery is contingent on the how an environment enables men to feel comfortable while they are vulnerable. Lyons et al. looked seven men's recovery from eating disorders and found four anecdotal themes [43]. My study provides a significantly larger sample taken in an environment that they often reported feeling high levels of comfort in being vulnerable and authentic.

\section{Eating Disorders as Mental IIIness}

The study of eating disorders is bracketed by the stigma associated with mental illness [23]. Individuals with mental illnesses often have an arduous time constructing recovery identities because of marginalization and deleterious stereotypes $[6,11,12$, 24, 25, 39, 59, 64]. Howard explained how recovery identities become an end-inthemselves, and how that limits an individual's ability to recover [32]. Studies on recovery identities for those with eating disorders have not examined the structural and substantive components of the narratives used or the role of gender in validating the identities, emotions, and experiences of those trying to recover.

\section{Sociology of Narrative}

In their most rudimentary form narratives are a "method of recapitulating past experiences by matching a...sequence of clauses to a sequence of events..." [37]: p. 359-360). Narratives can draw from any combination of the past, present, and future. A narrative is not evaluated on the truthful or logical nature of its content, but on the level of verisimilitude the narrative structure or arc brings to bear between its content and similar instances [7]. A narrative can, therefore, gain more purchase when it is appears to follow a similar trajectory to one's experiences. I differentiate narratives and stories in two ways. One, a narrative is the underlying pattern or set of qualities that underwrite a set of stories, whereas a story is the depiction of a particular snippet or event of only partial length. Two, we can easily imagine being satisfied telling a story about something in our lives in a multitude of ways. By contrast, narratives, because they are the expression of what persists throughout a series of stories and their trajectory the stories take when combined, exist as they do because the repeat occurrences within stories are representative of the underlying qualities of the narrator. 
The narratives individuals or groups use affect their ability to realize their objectives. They set the bounds on the perceived trajectories one's life might take. Studies in the sociology of narrative have found that the use of particular narratives are consequential in the outcomes for those suffering addiction [24] and those who have experience domestic abuse and/or sexual assault [34, 42, 48, 49, 54, 75]. Brown found that individuals in a support group who used a narrative where the individual transitions from the recipient of services, support and information to the dispenser of such capital were more likely than their peers to successfully recover (1991). I draw off work in the sociology of narrative to make sense of the mechanisms affecting the ability of individuals with eating disorders to recover, their lived experiences, and the extent to which particular narratives influence recovery outcomes.

\section{Methods}

My data derives from the accounts of 200 unique individuals living in the United States who self-reported having one or more eating disorders. I performed a stratified, purposive sample consisting of 100 women and 100 men; 50 each who have self-reported relapsing and 50 who have not. These accounts were taken from Tumblr, which is a social media platform, and eating disorder support group websites. Twenty accounts each of men and women were taken from the eating disorder support group websites, and 80 accounts of men and women were taken from Tumblr. By utilizing accounts from both websites specifically geared towards eating disorder recovery and general social media platform, I controlled for how subjects might talk within solely the eating disorder community and in a broader population. The advantage of these websites is that account holders can post without preset scripts, whereas the hegemonic narrative structures of support group meetings might preclude such individuality (i.e., 12 step programs) [48, 49]. The non-intervening nature of this approach avoided the risk of hampering their recovery or interfering with their therapy regiment. Also, utilizing online forums allows access to a larger community with more varied characteristics than an ED Anonymous meeting and enables for a larger sample size. Account holders can post photographs, videos, notes, and share the postings of others. As a result, they can express themselves at greater length, in greater frequency, through more mediums, and with a range of metaphorical devices that testimonials in meetings do not allow for. By having access to the account histories, I observe what people said, felt, and did in the past. This allows for richer information than most interviewing methods that would limit the data to the reflections of their respondents about their past feelings and memories and may change over time [35].

The accounts in my sample were selected in the following ways. For accounts on Tumblr, I first searched for posts using conventional hashtags and phrases used by members of the eating disorder recovery community. Hashtags are expressions that account holders use to link their posts to other posts of a like theme or subject (ex. \#edrecovery, \#edrelapse, \#healing, \#edproblems, \#tw). I utilized a random number generator to select the posts. If the posted was not original, I went to the account that created the content because it would be most 
illustrative of their experience as opposed to someone you might have reposted for one of many reasons. The reposts were also used as a way of confirming, rejecting, and/or adding nuance the initial facticity of analyses of the original posts. All subjects had to have said their gender and that they were recovery from one or more eating disorders through their original content. The data collection method for eating disorder support forums was similar. I used a random number generator to select a discussion thread, and then again to select a particular post within that thread. I used open-source software to download all the account history, including all posts and reposts. To ensure completeness, I randomly went through some of these accounts in full and manually confirmed that all the postings were included in the downloading process.

For all 200 accounts, I recorded self-reported biographical and demographic information of the account holders that such as age, geographic location, sex, gender, sexual orientation, occupation, and housing status into a spreadsheet. Subjects provided rich biographical information but were inconsistent in sharing the same set of demographic variables that would have been needed for a more intersectional analysis. All accounts were required to have the subject mentioned their gender and attest to recovery from an eating disorder. I stratified these accounts based on man/woman identification and if they reported having a relapse. No subjects happened to report being transgender or nonbinary.

The first round of coding was done inductively by manually reviewing individual posts to identify themes and variances between subjects, focusing on the subject (what the post was about) and nature (i.e., inspirational, relational, aspirational, struggles) of the posts for which the account holder was the original poster [13, 41]. I constructed a set of typologies that organized the narrative forms and descriptive language between the various account holders (Baily 1994) [36]. Typological construction is done a posteriori, meaning that it is created to sort the data and not for the data to be molded or abridged to fit an a priori model. To ensure that my set of typologies was exhaustive, I conducted a secondary round of deductive coding, this time also noting materials that account holders took from other accounts and reposted [4]. These replicated materials were used to ensure the reliability of their typological fit and that my coding was accurate. Most subjects in the sample had several hundred original posts and reposts. The subjects in the sample only relied on one narrative type.

Narrative analysis is a particularly valuable method for discerning the aspects of an individual's life which persist and those that change, how individuals make sense of their life and their social world, and the social and linguistic constructions which structure individual's sense making activities [7, 37]. I focused on the used to describe their eating disorders and their relationship to them, the arcs of their posts and any trends in path to recovery, and the presences of gendered language, if any, in any of the subject's account material. To illustrate the unique influence of narrative structure and narrative content on an individual's ability to recover, I tallied the proportion of self-reported relapse by narrative type. 


\section{Results}

The individuals in the sample lived throughout the United States, ranging from teenagers in high school to adults in their 50's. Many of the men and women in my sample reported having had different types of eating disorders throughout their life. The account histories ranged from about 5 months to over 4 years. Some had gone to in-patient treatment facilities, some to hospitals, and some had reported that they had not sought medical treatment for any health complications because of their eating disorder. Many of these individuals reported seeing a therapist and going to a support group. Some, however, reported not receiving any medical, psychiatric, or psychological therapy for their disorder. Despite the vast array of biographical and demographic characteristics of the individuals in this sample the patterned way by which individual talked about themselves, their eating disorder, and the relationship with them was starkly apparent. The results were consistent between the subjects taken from Tumblr and those taken from the eating disorder support group websites. Through the narrative analysis of 200 accounts, I identified and labelled four distinct, mutually exclusive types of recovery narrative utilized by account holders: Ecological, Sickened, Abused, and Warrior (See Table 1 and Fig. 1). These four narrative types are gendered, in the language and gender roles used within them and in the disparate impact of who uses them. Men only used the Warrior narrative. As illustrated in Table 2, the Warrior or Abused types had the highest proportions of account holders who self-reported relapsing. Given the distinct correlates between gender, narrative type, and the proportion of self-reported relapse, these findings demonstrate that the qualitative experience of having an eating disorder and recovering from it are different between women and men.

Note that the individuals in this study only used one narrative. The onenarrative approach persisted even as they engaged with others in these forums and Tumblr who used the other narratives. And, individuals in this study would acknowledge other's use of different narratives and as no less valid than their own. For example, it was common to see notes of support like "You're a Warrior, keeping fighting" to an individual using a warrior narrative but coming from individuals using any one of the four narratives. And, individuals could have had any one or multiple EDs and used any one of the four narratives.

Table 1 Characteristics of eating disorder narratives

\begin{tabular}{|c|c|c|c|c|}
\hline \multirow{2}{*}{$\frac{\text { Class }}{\text { Type }}$} & \multicolumn{2}{|l|}{ Under attack } & \multicolumn{2}{|l|}{ Rejuvenation-focused } \\
\hline & Warrior & Abused & Sickened & Ecological \\
\hline Arc & Episodic & Static & Cyclical or Parabolic & Logistic \\
\hline Resolution & None & None without fracture & $\begin{array}{c}\text { Achievable, some- } \\
\text { times temporary }\end{array}$ & Deontic \\
\hline Thematic language & $\begin{array}{l}\text { Evil, } \\
\text { Attack, } \\
\text { On guard }\end{array}$ & "He", Hurt, Bully & Sick, ill, past, healing & $\begin{array}{l}\text { Body as ecosystem, } \\
\text { balance, harmony, } \\
\text { center }\end{array}$ \\
\hline
\end{tabular}


Narrative: Sickened

Arc: Cyclical/Parabolic

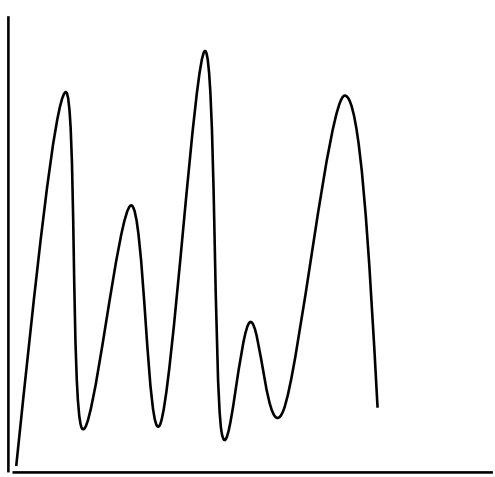

Narrative: Warrior Arc: Episodic

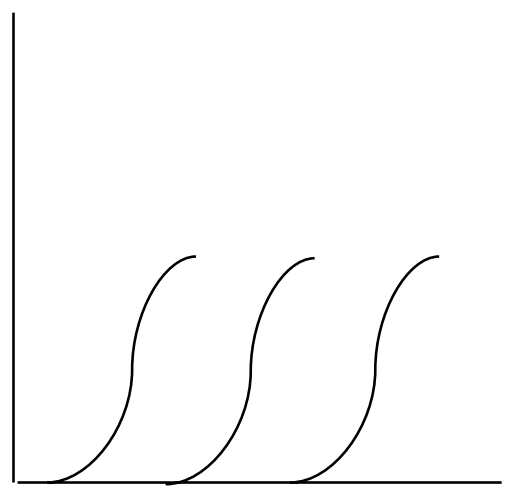

Narrative: Ecological Arc: Deontic

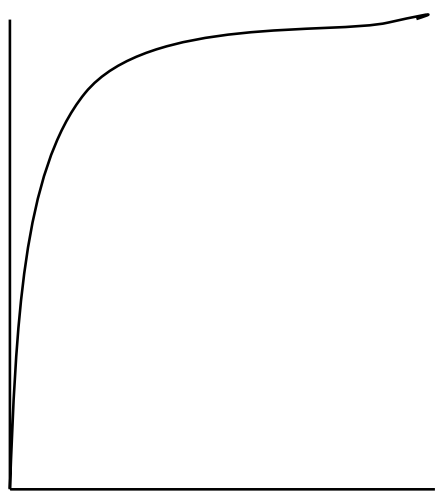

Narrative: Abused Arc: Static, unless major break

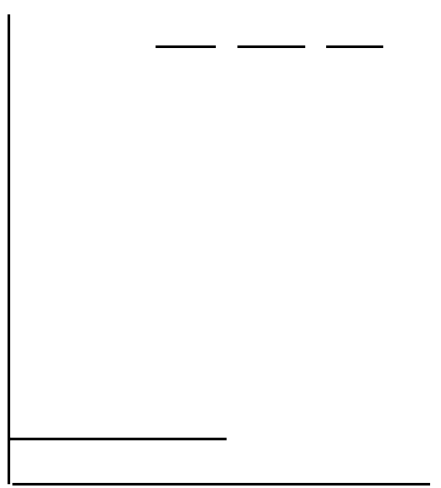

Fig. 1 Graphical representation of narrative arc structures

Table 2 Classification of sample population

\begin{tabular}{|c|c|c|c|c|c|c|}
\hline & & \multicolumn{2}{|l|}{ Women } & \multicolumn{2}{|l|}{ Men } & \\
\hline & & $\begin{array}{l}\text { Reported } \\
\text { relapse }\end{array}$ & $\begin{array}{l}\text { Didn't report } \\
\text { relapsing }\end{array}$ & $\begin{array}{l}\text { Reported } \\
\text { relapse }\end{array}$ & $\begin{array}{l}\text { Didn't report } \\
\text { relapsing }\end{array}$ & \\
\hline \multirow[t]{2}{*}{ Attacked } & Warrior & 15 & 6 & 50 & 50 & 121 \\
\hline & Abused & 19 & 5 & - & - & 24 \\
\hline \multirow[t]{3}{*}{ Rejuvenation } & Sickened & 6 & 18 & - & - & 24 \\
\hline & Ecological & 10 & 21 & - & - & 31 \\
\hline & & 50 & 50 & 50 & 50 & 200 \\
\hline
\end{tabular}


There was also no normative pressure to report relapsing, overcome a compulsion to relapse, or having gone a period of time without an urge to relapse. Whether an account holder was relapsing, struggling to recover, or in a prolonged period of recovery, the digital communities commenting on the account holder's posts were conspicuously supportive, never shaming, doubting, or ridicule. The ecological, sickened, abused, and warrior narratives were correlated with different rates of relapse, used different language, and had distinct narrative structures.

\section{Ecological}

The ecological narrative was the least common of the four types and only used by women. With only 10 of the 31 individuals self-reporting to have relapsed, those using the Ecological narrative were also the second least likely group to self-report relapsing after those using the Sickened narrative (see Table 2). The modus operandi of the ecological narrative is for the individual to achieve a greater balance in life. These individuals consistently identified the cause of their eating disorders because of focusing too much on improving one aspect of their life to the detriment of other aspects of their physical, psychological, and social wellbeing. A woman in college said that of her recovery that she had to learn to "try and find internal things about yourself that you love" and "let myself feel guilt...joy...wonder." Their recovery is described as a process of developing a greater sense of balance or of "blossoming and becoming."

The structure and linguistic content of the ecological narrative is the most distinct of the four narrative types found in the sample. The narrative arc is logistic, meaning that the path to recovery was consistently characterized by significant initial progress and less extreme but nevertheless continual refinement throughout the later periods of recovery (See Fig. 1). The resolution in an ecological narrative is continual refinement, getting closer to harmony. While the narrative structure does not have an endpoint or conclusion, its deontic process reduces the influence previous triggers have on an individual. The objective of the ecological narrative is the reduction of vulnerabilities that could give cause to relapse. Because the ecological narrative is driven by a preoccupation with mitigating one's vulnerability to relapsing, the fact that only women used this narrative is consistent with previous research's findings that "vulnerability is a core component of femininity" [30: p. 84].

The word choice used in the ecological narrative is highly naturalistic. Users frequently analogized their bodies and mind to that of an ecosystem, reaffirmed the utility of food as natural and necessary, and made prolific use of memes, videos, and photos that contained images of nature. For some, the ecological narrative was also a route for spiritual (re-)discovery, with the goals of eating and living an overall life of "balance not clean," overly restrictive habits.

The desire to find a perpetual sense of calm, balance, and a harmonized way of being in the world is a far less contentious recovery project than those found in the Abused or Warrior narratives. It is also more reflective and introspective than is expressed in the Sickened narrative. The emphasis on finding harmony, tranquility, and peace is also 
more consistent with typical feminine norms than it is with raucous, instigating, and aggressive traits associated with men [44].

\section{Sickened}

Those who found the sickened narrative type compelling likened their experiences with eating disorders to a severe cold or flu. The sickened narrative is the most dynamic of the four narrative types found in the sample, often composed of a series marked shifts, for better and worse, between healthy and unhealthy relationships with food and their body image (See Fig. 1). With only 6 of the 24 individuals using a sickened narrative reporting to have relapsed, it had the lowest proportion of relapse in the sample (See Table 2).

When individuals equated having an eating disorder to having been sick, the eating disorder became seen as neither a result of personal imbalances in one's lifestyle, like the ecological narrative, nor as a targeted onslaught against them, like the abused and warrior narratives discussed below. They consistently refrained from attributing any personal shortcomings or mistakes to the reasons that lead to their disorder. Additionally, they did not construct a victim identity. Instead, recovery was seen as a process through which individuals return to a level of good health that they had prior to their eating disorder. Their eating disorder was a "poison." As one woman stated, their experiences with their eating disorder(s) were now a faded "shadow that hovered over my life."

The fact that the sickened narrative had the lowest proportion of those reporting to have relapsed should make some intuitive sense when we compare its narrative structure and linguistic content to the other three types. The preoccupation with healing, care, and offering ways of healing to others is consistent with the gendered social construction of motherhood [2]. The individuals who used an ecological narrative frequently warned advice seekers of potential triggers, prefacing their suggestions with "don't let this ED trick you." While individuals who used the sickened narrative were the most likely group to provide recovery advice to others, they were not immune to relapse. Just like contracting the flu, those who reported the pressures inciting them to relapse saw such instances as fleeting aberrations from otherwise meaningful steps towards a full recovery. They described the periods of their lives with an eating disorder as "when I was sick," and their recovery journey as one wherein they are attaining increasingly better health to the point when they can reduce the chance of relapse to zero. Just like a person can get the flu multiple times throughout the course of her or his life and still be seen as living a healthy life, these individuals felt positive about the recovery so long as the frequency of such hiccups and impulses to relapse lessened. This general sense of optimism was pervasive and clearly present even when the sickened narrative took cyclical turns between pressures to relapse, actually doing so, and recovery (See Fig. 1). 


\section{Abused}

The abused narrative is the most clearly gendered and the bleakest of all four narrative types. Just like those who used the ecological and sickened narratives, only women used the abused narrative. Out of the 24 individuals in the sample who used the abused narrative, 19 reported relapsing; the highest proportion to report relapsing (See Table 2). Without even the possibility of a full recovery in sight, the abused narrative structurally lacks a path to transition from disorder to recovery (See Fig. 1).

Those using an abused narrative felt controlled by their eating disorder and forced to "do what the eating disorder wants you to do." Individuals using the abused narratives saw themselves as powerless to the overwhelming power, influence, and "the voices" that their eating disorder can have over them; reflecting that "Your ED wants you to [relapse]" and that "you are stuck under its weight." One woman noted that "I had no choice but to comply and follow the rules." Like many individuals in an abusive relationship with another person, individuals frequently expressed the sentiment that they would "never be good enough" and could never be separated from his or her eating disorder(s) regardless of their dire want to do so. Despite the subject's stated intent of "working on breaking up with my eating disorder," the psychic control of the eating disorder over them prevails. As one woman tragically and eerily stated, "Your ED will always think of a reason to go back to him."

More than just using language that depicts a relationship, the abused narrative is highly gendered to the point of pronoun usage. Eating disorders were routinely referred to as "He," even though no individual reported having been in an abusive relationship with a man or woman. The person striving for recovery is in a constantly vulnerable and submissive position to their eating disorder(s). They are victims, and their disorders were often noted as bullies and bosses. One woman wrote that the only way she could meaningfully progress in her recovery was to "Defy your disorder. Give your disorder a huge fuck you it deserves and take back the control it took from you." And while it is not uncommon for individuals to avoid interpersonal relationships while suffering from an eating disorder, individuals overwhelmingly noted that the crippling fear of imminent relapse made it such that they were not "allowed to go out with friends." Instances of more robust recoveries were only achieved after a sharp break or wanted "escape" such as a hospitalization or change in housing. This is akin to an intervention orchestrated by domestic abuse intervention specialists.

\section{Warrior}

The warrior narrative is colored by a persistent sense of foreboding and being under attack. Like an epic series of battles, the narrative arc is episodic and, as a result, lacks even the possibility of a resolution (See Fig. 1). It is a narrative wherein the individual in recovery is constantly battling with his/her disorder and lacks even an idea of what a recovered self would be like. To recover, as one subject noted, 
required one to "always have to be on guard." With 15 out of 21 women using a warrior narrative reporting to have relapsed, the warrior narrative had the second highest rate of reported relapse after the abused narrative (See Table 2). This was also the only narrative type that men used. Due to the stratified sampling method, having 50 men who reported relapsing and 50 who did not in this sample should not be taken as suggesting that the relapse rate for men using the warrior narrative is 50 percent.

It is difficult to overstress the extent to which individuals using the Warrior narrative feel as though they might at any moment face pressure to relapse that they cannot overcome. As one subject remarked, the eating disorder was trying to force her to "surrender" and "wants me to continue to kill myself." These immense forces pressuring an individual to relapse are not depicted as a product of one's imbalance, health, or history; they are seen as manifesting at any time, with or without cause.

The warrior narrative is also not like a soldier who shares in a common struggle with others. The struggles and fear that these individuals faced were depicted individualistically, especially more so than the subjects using either the ecological or sickened narratives. "It's me against my disease," remarked one teenage male. Their depictions of moments of extreme pressure consistently held them in strict isolation, on the run and/or waging an epic battle. A young man in college explained, "I can't surrender....it wants to kill me."

A feature of the warrior narrative which makes it irresolvable is its episodic quality (See Fig. 1). Unlike those who used ecological and sickened narratives, Warriors posts focused far less on general life course events, both day-to-day and milestones. Instead of detailing a return to some level of normalcy, posts were expressions of pains and struggles whose chronological order made no difference. The warrior narrative lacks a plotline, with each post being one of a multitude of battles, in no way contingent on prior struggles.

With a recovery narrative that places the individual on an enduring brink of relapse, it is perhaps not surprising that subjects who employed a warrior narrative were almost four times more likely to self-report relapsing than not (See Table 2). The replacement of an unhealthy preoccupation with food and body for an irresolvable unease with the potential of relapsing does not provide room for Warriors to pave a harmonious life.

Men were only Warriors. The language used within this narrative type is consistent with traits and actions more commonly associated with men. Warriors routinely used words such as attack, battle, fight, conquer, and overcome. The violent language and carnal imagery are more consistent with commonplace masculine attributes and the practice of confronting a perceived danger [15, 30]. The men's exclusive use of the warrior narrative, a profound manifestation of toxic masculinity, makes sense to the extent that narratives with stereotypically feminine content as they combat feminized illnesses would challenge their already shaken senses of self.

Just as the ecological, sickened, and abused narratives are replete with gendered language and devices, the warrior narrative was just as ripe for gender usage. Whereas the sickened narrative utilized a maternal motif, the abused narrative anthropomorphizes eating disorders as violent, domineering men, and the ecological appeals to feminized norms of tranquility and harmony, the warrior narrative made 
extensive use of conventionally male gender roles and characteristics in hopes of empowering individuals to fight through their present disorder.

This research has shown that for many individuals with eating disorders gender matters. And this is true in cases when gender may not have played a significant role in causing the disorder. It affects the relevancy of certain narrative types to the experiences, notions of self, and pressures incumbent on individuals in developing eating disorders and those striving for recovery. Such a position should not be read as a gender essentialist argument in the traditional sense. This research does not suggest that anything inherent in the characteristics of a given narrative must be gendered. Rather the recovery narratives employed, and the identity (re-)construction throughout have routinely presented themselves through gendered language and normative gender roles. Strong usage of gendered language and gender roles was consistently used throughout each narrative type. There is nothing inherent to a given narrative (its arc, central conflict, moral, theme, etc.) that requires it to be gendered. Instead, it is the gendered language and character roles used to bring life to the narrative skeleton of a story that engenders it. While gender played an important role in the narratives and recovery identities of all accounts in the sample, there is nothing about an individual's identity that requires it to be gendered at all, let alone play a pivotal role in one's sense of self [73]. Given the ubiquitous nature of gender in, and not of, narratives, the performative tools and mechanisms by which one constructs the self through narrative are gendered essentially [8, 9, 38, 62, 63]. The fact that the gendered language in these narratives relied on a binary understanding of gender is not surprising and likely a product of the research subjects being cisgender and the greater salience of gender stereotypes.

There is sound intuitive reason behind why gender becomes a particularly salient feature of a recovery narrative. When we tell a story about our lives, we do so in a way that represents aspects of who we are. In a period of recovery, when an individual must alter commanding features of their identity, individuals will be more reliant on normative concepts because they provide a surer foundation to their fragile self. When major aspects of a person's identity are under pressure or charging, they appear to rely on identities that are on surer footing.

\section{Conclusion}

This study found that the experiences of having eating disorders and recovering from them were different between men and women. A typology consisting of four narratives was constructed from a sample of 200 account holders who reported having eating disorders on Tumblr and eating disorder recovery support forums. The proportion of subjects reporting to have relapsed varied by narrative style (see Table 2). Women in the sample used any one of the four narrative types, whereas men only used the warrior narrative. The warrior narrative, saturated with stereotypically masculine vocabulary, was heavily associated with relapsing when used by women. The potential to adopt a new narrative is more plausible for women than it is for men because three of the narratives drew heavily off feminine gender roles and only one 
utilized masculine gender roles. Men in this study lack a relatable narrative to turn to that can guide them to better outcomes.

This research synthesizes the insights from the sociologies of eating disorders, narrative, gender roles, and masculinity studies to provide insight into the lived experiences of over 30 million Americans suffering from debilitating, and sometimes lethal, disorders. These findings suggest that using narrative analysis is insightful to understand the life course outcomes of those developing or reconstructing identities more generally. By being more attuned to the various qualities which constitute an individual's identity, researchers can better interrogate the utility, applicability, and function of a given narrative and its content. At a clinical level, this paper shows that a multitude of relatable narrative types are necessary for ensuring more successful recoveries for a wider array of individuals with eating disorders and/or other mental health ailments. Given that the experiences of those with eating disorders are gendered, those working to combat this pandemic, including clinicians, non-profit workers, and those in the news and entertainment industries, should be mindful not to reinforce the stereotype of the person with an eating disorder as being a frail, middle-to-upper class, white, woman in her late teens to early twenties.

Prior studies in the sociology of narrative have found that narratives can play a consequential role in the outcomes for those in recovery from illness and trauma. The research presented is consistent will such earlier work, finding a correlation between narrative type and self-reported relapse for other health problems [24]. This paper expands that understanding by showing that gender affects the narrative type and narrative content and may be associated with differing rates of relapse.

Previous research on the social-psychological factors contributing to the development of eating disorders have suggested that unrealistic conceptions of ideal feminine beauty have been a source of pressure for millions of women with eating disorders. Such ideals, if not replaced, can serve as hindrances during the recovery process. The findings presented in this paper suggest that social-psychological factors also influenced men, but did so using masculine words, phrases, and roles. This research expands on the incipient research found within the growing lacuna in masculinity studies and psychiatric studies about boys and men with eating disorders [45]. By drawing from the sociological research on gender roles and the sociology of narrative, this research extends sociological studies on eating disorders to men by showing that male gender roles and stereotypes were contributing factors to the success of their recoveries.

The use of digital space for recovery, wherein individuals can engage with clinicians and forge positive, supportive communities, is a relatively new development in the treatment of mental health problems. Subjects in this sample utilized social media and forums to find support, strategies for a better and lasting recovery, and to find positive ways of being-in-the-world. The online eating disorder support forums and discursive space on Tumblr covered in this sample were highly supportive, noncritical, and welcoming spaces. Individuals in the sample spoke with a great deal of candor, expressing intimate details about their lives far beyond their experiences with eating disorders. On Tumblr, individuals who reported not ever having an eating disorder supported those in recovery. The opportunity for members of marginalized groups to express themselves openly to society at-large does not sit well in the 
modern period of mental health as described by Foucault in his tome Madness and Civilization [20]. He assessed the modern experiences during the nineteenth and twentieth centuries of the mad and/or mentally ill as one of isolation and confinement. Instead, this study suggests that digital space might serve as a point of re-entry for the formerly isolated. This is not to say that the digital space is all-inclusive. While there is rampant cyberbullying and vitriolic pro-anorexia and pro-bulimia discourses online, the growth of these open, inclusive recovery communities in online spaces, and their newfound function in medically prescribed treatment regimens, may signal the birth of a new, more inclusive stage in mental health promotion [72].

Generating a generalizable sample of a marginalized population is often difficult. Like many mental health issues, the stigma associated with eating disorders disincentivizes individuals from being public with their condition; especially those who do not fit the stereotype of someone with that condition. This study conducted a purposive, stratified sample consisting of 50 account holders each of: women who reported relapsing, women who did not, men who reported relapsing, and men who did not. A sample of 200 accounts done in this way cannot say conclusively that the 30 million Americans with eating disorders use only one of these four narrative types or in the same proportions, nor can it measure the unique effect of narrative type on the rate of relapse. Nonetheless, the ubiquity of gender and of narratives in self-understanding means that the findings of this study demonstrate the importance of understanding how gender affects people recovering from illness [73].

Future research should examine the potential gendered pressures that lead men to developing eating disorders. Subsequent clinical studies are needed to properly measure this variation and control for other psychological factors that affect one's ability to recover. Interviewing, both online and in clinical settings, and surveying can be especially helpful methods to develop our understanding of how gender and narratives play a role in the lives of those with eating disorders. Such research would also enable us to account for factors that have led to the growth in the number of men in the United States with eating disorders and 37 percent growth in hospitalizations because of them between 2000 and 2006 [76].

Funding This article was not submitted elsewhere for simultaneous consideration and has not been published elsewhere in part or full. This article contains the entirety of the study. The data has been published honestly and was collected consistent with the prescribed IRB protocols. Informed consent was not applicable for deriving the data set. There are no conflicts of interest, financial or otherwise. Financial support was provided by Department of Sociology at the University of California-Irvine. I am grateful for the many members of the Department of Sociology at the University of California-Irvine, faculty and graduate students, for their generous suggestions and feedback.

Open Access This article is licensed under a Creative Commons Attribution 4.0 International License, which permits use, sharing, adaptation, distribution and reproduction in any medium or format, as long as you give appropriate credit to the original author(s) and the source, provide a link to the Creative Commons licence, and indicate if changes were made. The images or other third party material in this article are included in the article's Creative Commons licence, unless indicated otherwise in a credit line to the material. If material is not included in the article's Creative Commons licence and your intended use is not permitted by statutory regulation or exceeds the permitted use, you will need to obtain permission directly from the copyright holder. To view a copy of this licence, visit http://creativecommons.org/licen ses/by/4.0/. 


\section{References}

1. American Psychiatric Association. (2011). American psychiatric association diagnostic and statistical manual of mental disorders (5th ed.). American Psychiatric Association.

2. Arendell, T. (2000). Conceiving and investigating motherhood: The decade's scholarship. Journal of Marriage and Family., 62(4), 1192-1207.

3. Bailey, K. D. (1994). Typologies and taxonomies: An introduction to classification techniques. Sage Publications.

4. Becker, H. (1940). Typology in the social science. American Sociological Review, 5(1), 40-55.

5. Bordo, S. (2003). Unbearable weight: Feminism, western culture, and the body. University of California Press.

6. Brown, D. J. (1991). The professional ex-: An alternative for exiting the deviant career. Sociological Quarterly, 32, 219-230.

7. Bruner, J. (1991). The narrative construction of reality. Critical Inquiry, 18, 1-21.

8. Butler, J. (1988). Performative acts and gender constitution. Theatre Journal, 40(4), 519-531.

9. Butler, J. (2004). Undoing gender. Routledge.

10. Chaiken, S., \& Pliner, P. (1987). Women, but not men, are what they eat: The effect of meal size and gender on perceived femininity and masculinity. Personality and Social Psychology, 13(2), 166-176.

11. Charmaz, K. (1991). Good days, bad days: The self in chronic illness and time. Rutgers University Press.

12. Charmaz, K. (1994). Identity dilemmas of chronically ill men. Sociological Quarterly, 35, 269-288.

13. Charmaz, K. (2006). Constructing grounded theory: A practical guide through qualitative analysis. Sage Publications.

14. Chen, A. S. (1999). Lives at the center of the periphery, lives at the periphery of the center: Chinese american masculinities and bargaining with hegemony. Gender \& Society, 13(5), 584-607.

15. Connell, R. W. (1995). Masculinities (2nd ed.). Polity Press.

16. Connell, R. W., \& Messerschmidt, J. W. (2005). Hegemonic masculinity: Rethinking the concept. Gender \& Society, 19(6), 829-859.

17 Courtenay, W. H. (2000). Constructions of masculinity and their influence on men's well-being: A theory of gender and health. Social Science \& Medicine, 50, 1385-1401.

18. Davids, C. M., \& Green, M. A. (2011). A preliminary investigation of body dissatisfaction and eating disorder symptomatology with bisexual individuals. Sex Roles, 65, 533-547.

19. Demetriou, D. Z. (2001). Connell's concept of hegemonic masculinity: A critique. Theory and Society, 30, 337-361.

20. Foucault, M. (2009). Madness and civilization. trans. J. Khalfa. Routledge.

21. Garrett, C. (1996). Recovery from anorexia nervosa: A durkheimian interpretation. Social Science and Medicine, 43(10), 1489-1506.

22. Gilmore, D. D. (1990). Manhood in the making. Yale University Press.

23. Goffman, E. (1963). Stigma: Notes on the management of spoiled identity. Prentice-Hall.

24. Granfield, R., \& Cloud, W. (1999). Coming clean: Overcoming addiction without treatment. New York University Press.

25. Gubrium, J. F., \& Holstein, J. A. (2001). Institutional selves: trouble identities in a postmodern world. Oxford University Press.

26. Haworth-Hoeppner, S. (2000). The critical shapes of body image: The role of culture and family in the production of eating disorders. Journal of Marriage and Family, 62, 212-227.

27. Haworth-Hoeppner, S., \& Maines, D. (2005). A sociological account of the persistence of invalidated anorexic identities. Symbolic Interaction, 28(1), 1-23.

28. Hesse-Biber, S., Marino, M., \& Watts-Roy, D. (1999). A longitudinal study of eating disorders among college women: Factors that influence recovery. Gender \& Society, 13(3), 385-408.

29. Hoek, H. W., \& van Hoeken, D. (2003). Review of the prevalence and incidence of eating disorders. International Journal of Eating Disorders, 34(4), 383-396.

30. Hollander, J. A. (2001). Vulnerability and dangerousness: The construction of gender through conversation about violence. Gender \& Society, 15(1), 83-109.

31. Hollander, J. A. (2004). The social context of focus groups. Journal of Contemporary Ethnography, 33(5), 602-637. 
32. Howard, J. (2006). Expecting and accepting: The temporal ambiguity of recovery identities. Social Psychology Quarterly, 69(4), 307-324.

33. Hudson, J. I., Hiripi, E., Pope Jr, H. G., \& Kessler, R. C. (2007). The prevalence and correlates of eating disorders in the national comorbidity survey replication. Biological Psychiatry, 61, 348-358.

34. Illouz, E. (2008). Triumphant suffering. Saving the modern soul: therapy, emotions and the culture of self-help. University of California Press.

35. Jerolmack, C., \& Khan, S. (2014). Talk is cheap: Ethnography and the attitudinal fallacy. Sociological Methods and Research, 43(2), 178-209.

36. Kluge, S. (2000). Empirically grounded construction of types and typologies in qualitative social research. Qualitative Social Research 1(1).

37. Labov, William. 1972. "The Transformation of Experience in Narrative Syntax." Language in the Inner City: Studies in the Black English Vernacular. Philadelphia, PA: University of Pennsylvania Press

38. Lamont, M. (2000). The dignity of working men: morality and the boundaries of race, class, and immigration. Russell Sage Foundation.

39. Link, B. G., Cullen, F. T., Frank, J., \& Wozniak, J. F. (1987). The social rejection of former mental patients: Understanding why labels matter. American Journal of Sociology, 92, 1461-1500.

40. Link, B. G., Struening, E., Cullen, F. T., \& Shrout, P. E. (1989). A modified labeling theory approach to mental disorders: An empirical assessment. American Sociological Review, 54, 400-423.

41 Lofland, J., David, A. S., Leon, A., \& Lyn, H. L. (2006). Analyzing social settings: A guide to qualitative observation and analysis (5th ed.). Thomson/Wadsworth.

42. Loseke, D. (2001). Lived realities and formula stories of battered women. In J. F. Gubrium \& J. A. Holstein (Eds.), Institutional selves: Troubled identities in a postmodern world (pp. 107-126). Oxford University Press.

43. Lyons, G., Sue, M., \& Tony, W. (2019). Disappearing in a female world: Men's experiences of having an eating disorder (ED) and how it impacts their lives. Issues in Mental Health Nursing, 40(7), 557-566.

44. Mosher, D. L., \& Tomkins, S. S. (1988). Scripting the macho man: Hypermasculine socialization and enculturation. Journal of Sex Research, 5(1), 60-84.

45. Nagata, J. M., Brown, T. A., Murray, S. B., \& Lavender, J. M. (2021). Eating disorders in boys and men. Springer.

46. Nye, R. A. (2005). Locating masculinity: Some recent work on men. Signs Journal of Women in Culture and Society, 30(3), 1937-1962.

47. Pascoe, C. J. (2005). 'Dude, you're a fag': Adolescent masculinity and the fag discourse. Sexualities, 8(3), 329-346.

48. Polletta, F. (2009). How to tell a new story about battering. Violence Against Women, 15, 1490-1508.

49. Polletta, F., Trigoso, M., Adams, B., \& Ebner, A. (2013). The limits of plot: Accounting for how women interpret stories of sexual assault. American Journal of Cultural Sociology, 1, 289-320.

50. Prus, R. C. (1989). Making sales. Sage.

51. Pyke, K. D. (1996). Class-based masculinities: The interdependence of gender, class, and interpersonal power. Gender \& Society, 10(5), 527-549.

52. Ricciadelli, R., \& Clow, K. (2009). Men, appearance, and cosmetic surgery: The role of self-esteem and comfort with the body. Canadian Journal of Sociology, 34(1), 105-134.

53. Saguy, A. C., \& Gruys, K. (2010). Morality and health: News media constructions of overweight and eating disorders. Social Problems, 57(2), 231-250.

54. Scheppele, K. L. (1992). Just the facts, ma'am: Sexualized violence, evidentiary habits, and the revision of truth. New York Law School Law Review, 37, 123-172.

55. Schippers, M. (2007). Recovering the feminine other: Masculinity, femininity, and gender hegemony. Theory \& Society, 36, 85-102.

56. Schrock, D., \& Schwalbe, M. (2009). Men, masculinity, and manhood acts. Annual Review of Sociology, 35, 277-295.

57. Siegel, J. A., \& Sawyer, K. B. (2020). "We don't talk about feelings or struggles like that": White men's experiences of eating disorders in the workplace. Psychology of Men \& Masculinities, 21(4), 533-544.

58. Smith, D. E., Marcus, M. D., Lewis, C., Fittzgibbon, M., \& Schreiner, P. (1998). Prevalence of binge eating disorder, obesity, and depression in a biracial cohort of young adults. Annals of Behavioral Medicine, 20, 227-232. 
59. Strauss, A. (1969). Mirrors and masks: The search for identity. The Free Press.

60. Striegel-Moore, R. H., \& Franko, D. L. (2003). Epidemiology of binge eating disorder. International Journal of Eating Disorders, 34, S19-S29.

61. Sublette, C. M., \& Martin, J. (2013). Let them eat cake, caviar, organic, and whole foods: American elitism, white trash dinner parties, and diet. Studies in Popular Culture, 36(1), 21-44.

62. Swidler, A. (1986). Culture in action: Symbols and strategies. American Sociological Review., 51(2), 273-286.

63. Swidler, A. (2001). Talk of love: How culture matters. University of Chicago Press.

64. Thoits, P. (1985). Self-labeling process in mental illness: The role of emotional deviance. American Journal of Sociology, 91, 221-249.

65. Thompson, B. W. (1994). A hunger so wide and so deep: A multiracial view of women's eating problems. University of Minnesota Press.

66 Wade, T. D., Keski-Rahkonen, A., \& Hudson, J. I. (2011). Epidemiology of eating disorders. In M. Tsuang \& M. Tohen (Eds.), Textbook in psychiatric epidemiology (pp. 343-360). Wiley.

67. Walstrom, M. (2000). 'The eating disorder is not you': Applying bakhtin's theories of analyzing narrative co-construction in an internet support group. Studies in Symbolic Interaction, 23, 241-260.

68. Wax, M. L., \& Cassell, J. (1990). The looking glass self: Introductory notes on anorexia nervosa. Mid-American Review of Sociology, 14(1-2), 135-143.

69. Webb, T. T., Joan Looby, E., \& Fults-McMurtery, R. (2004). African American men's perceptions of body figure attractiveness: An acculturation study. Journal of Black Studies, 34(5), 370-385.

70. Weintraub, K. (2011). Eating disorders are a guy thing, too. Boston Globe.

71. West, C., \& Zimmerman, D. H. (1987). Doing gender. Gender \& Society, 1(2), 125-151.

72. Whitehead, K. (2010). 'Hunger hurts but starving works': A case study of gendered practices in the online pro-eating-disorder community. Canadian Journal of Sociology, 34(4), 595-626.

73. Witt, C. (2011). The metaphysics of gender. Oxford University Press.

74. Wolf, N. (1991). The beauty myth: How images of beauty are used against women. Anchor Books.

75. Wood, J. (2001). The normalization of violence in heterosexual romantic relationships: Women's narratives of love and violence. Journal of Social and Personal Relationships, 18, 239-261.

76. Zhao, Y., William, E. (2009). Hospitalizations from eating disorders 1999-2006. Statistical brief No.70. Agency for Healthcare Research and Quality.

Publisher's Note Springer Nature remains neutral with regard to jurisdictional claims in published maps and institutional affiliations. 